\title{
The Association of World Health Organisation (WHO) Safe Community Programme with Death Rate from Motorcycle Accidents in Iran
}

\author{
Alireza Moghisi' ${ }^{1}$ Reza Mohammadi ${ }^{1}$, Leif Svanstrom ${ }^{1}$, Hossein Kazemeini2 ${ }^{*}$ \\ ${ }^{1}$ Department of Public Health Science, Norrbacka, Karolinska Institute, Stockholm, Sweden \\ ${ }^{2}$ PHC Center, Ministry of Health and Medical Education, Tehran, Iran \\ Email: ${ }^{*}$ kazemeini2002@yahoo.com
}

Received 5 July 2014; revised 9 August 2014; accepted 26 August 2014

Copyright (C) 2014 by authors and Scientific Research Publishing Inc.

This work is licensed under the Creative Commons Attribution International License (CC BY). http://creativecommons.org/licenses/by/4.0/

(c) (i) Open Access

\begin{abstract}
Background: Many developing countries are facing the problem of rapidly rising death rate from fatal accidents involving motorcycles. Objective: To determine the effect of participation and implementation of the World Health Organization (WHO) Safe Community Programme on death rate from fatal motorcycle accidents. Methods: Motorcycle' fatal accident data were obtained from forensic medicine departments and hospital records in 11 cities located in three provinces in Iran during 2006-2007. Data were analyzed using chi-square and ANOVA tests. Fidelity of the data was safeguarded by using national security coding for each individual involved in the accident. Results: The highest death rate was found in the Fars province followed by Khorasan and Bushehr provinces. In Fars province, the highest mortality rate was found in Niriz city, which did not implement the Safe Community Programme and the lowest death rate was reported from Arsanjan city participating in Safe Community. Similar results were found in the Khorasan province. In Busher province, the highest death rate was found in Busher city participating in the program and the lowest in Genaveh city-not participating in the program. Among sex and age groups, males aged 19 - 39 years old had a highest death rate. Half of the death occurred at the accident scene-25\% during a transfer to the hospital and $25 \%$ of death occurred at the hospital. Conclusions: The Safe Community Programme is a promising model to prevent death from fatal motorcycle accidents in urban areas in Iran.
\end{abstract}

\section{Keywords}

Motorcyclists' Death, Epidemiology

\footnotetext{
${ }^{*}$ Corresponding author.
}

How to cite this paper: Moghisi, A., Mohammadi, R., Svanstrom, L. and Kazemeini, H. (2014) The Association of World Health Organisation (WHO) Safe Community Programme with Death Rate from Motorcycle Accidents in Iran. Open Journal of Preventive Medicine, 4, 681-688. http://dx.doi.org/10.4236/ojpm.2014.48077 


\section{Introduction}

Road traffic injuries accounting for ninth leading cause of death contribute significantly the burden of disease throughout the world, particularly in developing countries [1]-[3]. About $90 \%$ of mortality from road traffic accidents occurs in low and middle income countries. In many countries, the majority of those injured in road traffic crashes are pedestrians, cyclists and motorcyclists (that is, motorcycles, motor scooters etc.). For instance, in 1994 in Malaysia, 57\% of all road deaths were riders of motorcycles [2] [3]. The number of road fatalities attributed to motorized two-wheelers in industrialized countries, where four-wheeled private vehicles are more prevalent, is also disproportionately high [2]. 15\% of deaths or seriously injuries on roads were recorded from $1 \%$ of road users in 1998 in Britain. Motorcycle riders accounted for less than 1\% of total road users but contributed to $15 \%$ of those killed or seriously injured on the roads. With increasing modernization in many developing countries, road traffic deaths are increasing, and traffic deaths are predicted to be the third most important health problem by 2020 [4]. Injuries to the head, following motorcycle accident, are a common cause of morbidity and mortality [5] [6]. Results from large-scale studies have suggested that injury and death rates decrease when helmet use rates increase with the implementation of the law [7] [8]. However, in both developing and developed countries, resistance to legislation on motorcycle helmets still coexists with debate on the effectiveness of motorcycle helmets in reducing morbidity and mortality.

Though helmet usage has been shown to be highly effective in reducing the adverse outcomes of motorcycle injuries and contributing to the reduction of health care expenses; arguments against helmets for motorcycle riders include the possibility that they decrease rider visibility and increase the risk of neck injuries existing and the effectiveness of helmets in reducing mortality is questionable [6] [9]. Whether the helmet causes more severe injury to the other part of the body of motorcyclists in motorcycles' accident is questionable? The effectiveness of mandatory use of a helmet in preventing incidence and severity of physical trauma has been evaluated, as well. Almost all studies have uniformly found that the presence of helmet laws, representing an external social control, contributes to the high helmet wearing rates in many countries reducing motorcycle-related morbidity and mortality [10] [11].

Many countries around the world are facing the problem of urbanization-a rapidly rising number of people injured or killed while riding two-wheelers-motorcycles and bicycles. A large proportion of the deaths and severe injuries result from injuries to the head. Helmets are effective in reducing the likelihood of head injuries, as well as their severity [12]. The social costs of motorcycle-related deaths and disabilities are high, not only through premature deaths and hospital admissions but also through costs of rehabilitation, lost income, sickness benefits, insurance, property, and legal consequences as well as personal costs of grief and suffering. As shown by many authors, increasing helmet use in the country is an important way to improving road safety [12].

Many studies have investigated the characteristics of motorcyclists such as their attitudes, knowledge, behaviors, riding frequency, traffic experience, and age of licensure. Motorcycles are considered an easy and inexpensive mode of transportation to use both in heavy traffic of large cities and countryside. The majority of motorcycle riders involved in road accidents are young males, especially under 20 years, who generally tend to adopt risky attitudes and behaviors having an increased risk of injury compared with older drivers.

Haddon matrix, a conceptual model, developed to understand motor vehicle injuries based on the "humanagent-environment” model is recommended to analysis of the event that is essential for determining injury mechanisms and guiding preventive efforts [10] [13].

Multiple explanatory factors are likely to be operated simultaneously to produce an injury occurrence (i.e. the helmet use and road conditions on motorcycle fatalities) and affect an injury outcome (i.e. access to high-quality treatment and rehabilitation) [14].

The safe community as a model to control injuries has been recognized by many cities nationwide. It is a conceptual model based on intersectoral collaboration and community participation. This study will compare mortality and morbidity of motorcycles' accident in safe community practicing cities and safe community non-practicing cities.

\section{Objectives}

To determine the effect of participation in the World Health Organization (WHO) Safe Community Programme on death rate from fatal motorcycle accidents in 11 cities located in three provinces in Iran.

\section{Materials and Methods}

Any study that measures and reports changes in injury rates compared to a control community in a WHO Des- 
ignated Safe Community (Designated Safe Communities are those that have undergone the formal WHO accreditation process on the basis of meeting the six eligibility criteria outlined below). Most of interventions that were applied in safe communities including; environmental modification, education, police re-enforcement and helmet vaccination during 2004-2007. Study designs that are comparison of motorcyclist's fatality in WHO safe community designated cities with non-designated safe community cities. Testing for an association between fatality rate and the type of city (safe community practicing with safe community non-practicing cities) in the study areas was performed [15].

\section{Data Source}

\subsection{Vital Registration System}

In this study, Vital Registration (VR) refers to the Death Registration System (DRS) operated by the Ministry of Health and Medical Education (MOHME). MOHME collects mortality data from district health centers. In rural areas, deaths are registered in 17,000 Health Houses and reported to the district health centers. At the district level, vital data are obtained from five sources, including all public and private hospitals, district cemeteries, the district office of the Forensic Medicine Organization, household visits by community health workers in rural areas, and information from community health volunteers [16].

\subsection{Hospital Statistics}

For several years, the MOHME has conducted household follow-up studies of injured victims that had received care and treatment at medical facilities. The purpose of these studies is to measure the incidence of injuries, the demographic characteristics of victims, and the epidemiological characteristics of injury-related events. The MOHME collected injury case information from all hospitals in 31 provinces in a specified period. Data is collated from the medical records of the victim, the DRS record for fatal cases, and an interview with household members of the victims. Our analysis uses data collected in 2005 and extrapolates this data to the provincial level in order to estimate the annual population incidence of injuries [17] [18].

Several data sources such as death record, hospital admissions, forensic medicine, and burden of disease reports were utilized and merged. All fatality data due to motorcycle accidents were extracted from the above sources existing in 11 cities (5 cities known to be a WHO safe community and 9 cities are not practicing safe community model) during 2006-2007.

\subsection{WHO Safe Community Model}

The WHO Safe Community model describes desirable features of a community oriented injury prevention policies. The process model used in Safe Community programs relies on input from local politicians, civil servants, representatives of non-governmental organizations, and public health workers to identify problems and implement actions. Implementation of the Safe Community program began in 1997 in Iran, the first city that fulfilled the criteria of becoming an international designated safe community was Kashmar city on 2007, subsequently the program expanded to more cities [10] [13].

Data were analyzed with chi-square for categorized data and analysis of variance for continuous data.

\section{Results}

This study revealed that the main age group of participants was aged between 18 - 29 years old (45\%) (Table 1).

Khorasan province with more than $65 \%$ of the motorcyclists has the highest rate among the 3 provinces in this study. Busher province placed at the north border of the Persian Gulf has 21\% of the motorcyclists, and Fars province has the least number of motorcyclists among the others with the proportional rate of $13 \%$. Within the each province, there are 2 groups of cities. Group one, which is also considered as a case, are those cities where the WHO safe community model is practicing for injury prevention and safety promotion activities. Except for the Bushehr and Fars where the result of safe community to the motorcyclists' death could not be demonstrated, the safe community of Khorasan, has a positive impact to the motorcyclists' death.

In Khorasan province, the number of motorcycles is more in safe communities practicing cities (55.4\%) compare to non-practicing safe communities (44.6\%). The death rate of motorcyclists is less in safe communities of Khorasan province includes Kashmar cities and Bardscan cities where both are internationally designated as a 
Table 1. Number and proportion of registered motorcycles existing in 11 cities in Iran by owner's age group, in practicing safe community cities verses non-practicing safe community cities, 2007.

\begin{tabular}{cccc}
\hline & \multicolumn{3}{c}{ Safe community groups } \\
\hline Characteristic & Safe community practicing & Safe community no practicing & All \\
\hline Participants, no. (\%) & $116,520(51.3 \%)$ & $110,540(48.7 \%)$ & $227,060(100 \%)$ \\
Owners age in years & & & $0(0)$ \\
$0-17$ & $0(0)$ & $0(0)$ & $100,629(44.3 \%)$ \\
$18-29$ & $52,434(45 \%)$ & $48,195(43.6 \%)$ & $71,594(31.5 \%)$ \\
$30-44$ & $33,790(29 \%)$ & $37,804(34.2 \%)$ & $28,343(12.5 \%)$ \\
$45-59$ & $15,963(13.7 \%)$ & $12,380(11.2 \%)$ & $26,494(11.6 \%)$ \\
\hline
\end{tabular}

WHO safe community since 2007, 2008 respectively (47\%). The non-practicing safe communities in the Khorasan province are cities of Ferdos and Torbat-e-Hydarieh. In these two cities death rate from motorcycle accidents is high $(53 \%)$.

The same picture was detected in Fars province. Arsanjan and Eglid are two cities that the WHO safe community model is practicing; the Arsanjan was designated as an international safe community on 2008. However, the impact of the WHO safe community to the motorcyclists' death is positive in these two cities compare to other cities of the province. They are Kazeron city and Niriz city (44.5\% vs. 55.5\%). However, death ate figures revealed that there are no differences in two groups of cities.

The story is slightly different in Bushehr province. Statistically no differences were determined in safe community practicing cities and none practicing safe community in Busher province in terms of fatality from motorcycle's accident. In Fars province, number of death from motorcycle accidents is slightly more in non-practicing safe community compare to practicing safe community. This may be because of better data collecting system in the later than the former. However, statistically this finding was not significant (Tables 2-4).

\section{Limitations of the Study}

A set of limitations lies in the data sources used in the study. The cause of death registry was not merged with the police report registry and hospital discharge registry. This could lead to an underestimation of magnitude of motorcyclists' fatalities. By using the social security number for each individual, this drawback has been overcome to some extent.

\section{Discussions}

In Many studies, including sixty-one observational studies, which were, performed worldwide the results in term of motorcyclists' death and injury were the same. In all studies motorcycle helmet found to reduce head injury in motorcyclists' crash. It is estimated that helmet reduces the risk of death by $42 \%$. In some articles helmet shown to reduce the risk of head injury by $69 \%$ [19]-[21]. No sufficient evidence for the effectiveness of helmet in protecting facial and neck injuries [12] [18] [22].

In traffic-related motorcycle accidents, injuries are sustained mainly by young adults posing a tremendous burden to affected individuals and society [14] [22]-[24]. Traffic related accidents prematurely interrupt the life of thousands of people, especially during the first decades of life in the economically active age range (adolescents and young adults aged 15 to 44 years), representing a serious socioeconomic and public health problem [25]. This study revealed that the main age group of participants was 18 - 29 years of age (45\%). Predominant age group of the motorcyclists in both case and the control cities are the young individual below 40 years of age. In these cities, most of the motorcyclists were using the motorcycle as the source of the family income. Most of them were the breadwinner to the family.

Some study emphasizes how crucial the first years of driving experience are and how wide the gap is in terms of socio-economic differences at this stage [14]. Even if based on nation-wide data referring to a single country, these findings might be transferable to other countries where the motorcycle injuries have a higher prevalence [26] in another study, which was performed in Sweden in an experimentally designed community. The effect of an organizational program on prevention of traffic related accidents was measured. The results showed a 50\% 
Table 2. Number and proportion of existing registered motorcycles in 11 cities in Iran in safe community practicing verses safe community non-practicing cities, 2007.

\begin{tabular}{|c|c|c|c|c|c|c|}
\hline \multirow[t]{2}{*}{ Province } & \multicolumn{6}{|c|}{ Number of motorcyclists } \\
\hline & SC & $\%$ & NSC & $\%$ & Total & $\%$ \\
\hline \multirow[t]{2}{*}{ Busher } & Busher city & 44 & Genaveh-Tangestan cities & 56 & \multirow{2}{*}{49,060} & \multirow{2}{*}{21.6} \\
\hline & 21,520 & 18.5 & 27540 & 25 & & \\
\hline \multirow[t]{2}{*}{ Khorasan } & Kashmar-Bardscan cities & 55.4 & Ferdos-Torbat-e-Hydarieh cities & 44.6 & \multirow{2}{*}{148,000} & \multirow{2}{*}{65.2} \\
\hline & 82,000 & 70.3 & 66,000 & 59.7 & & \\
\hline \multirow[t]{2}{*}{ Fars } & Arsanjan-Eghlid cities & 43.4 & Kazeron-Niriz cities & 56.7 & \multirow{2}{*}{30,000} & \multirow{2}{*}{13.2} \\
\hline & 13,000 & 11.2 & 17,000 & 15.6 & & \\
\hline Total & 116,520 & 51.3 & 110,540 & 48.7 & 227,060 & 100 \\
\hline
\end{tabular}

SC: practicing safe community; NSC: non-practicing safe community.

Table 3. Death rate among the motorcyclists by 100,000 motorcycles in 11 cities in Iran, in practicing safe community cities verses non-practicing safe community cities, 2007.

\begin{tabular}{|c|c|c|c|c|c|}
\hline \multirow{2}{*}{ Province } & \multicolumn{2}{|c|}{ Safe community practicing cities } & \multicolumn{2}{|c|}{ Safe community none practicing cities } & \multirow{2}{*}{ P value } \\
\hline & City & Death rate & City & Death rate & \\
\hline Busher & Busher & 41.7 & Genaveh & 41.8 & 0.0763 \\
\hline \multirow{2}{*}{ Khorasan } & Kashmar city & 34.2 & Ferdos city & 75 & \multirow{2}{*}{0.0369} \\
\hline & Bardscan city & 16 & Torbat-e-Heydarieh city & 200 & \\
\hline \multirow{2}{*}{ Fars } & Arsanjan city & 225 & Niriz city & 254 & \multirow{2}{*}{0.0492} \\
\hline & Eghlid city & 122 & Kazeron city & 95.7 & \\
\hline
\end{tabular}

Table 4. Number and proportion of motorcyclists' fatality in 11 cities in Iran in practicing safe community cities verses nonpracticing safe community cities, 2007.

\begin{tabular}{cccc}
\hline Province & Safe community groups & No (\%) \\
\hline Busher & NSC & $8(11.8)$ \\
& Khorasan & SC & $9(14.8)$ \\
& Fars & NSC & $36(52.1)$ \\
& SC & $32(52.4)$ \\
& NSC & $20(36.1)$ \\
\hline
\end{tabular}

SC: safe community practicing group; NSC: safe community non-practicing group.

reduction in the relative risk for moderate and mild injuries. The persons who most benefited from the program were pedestrians, cyclists, and motorcyclists [11] [15] [27] [28].

This study does not peruse to measure the impact of helmet as a goal. In another study performed with the same setting measuring attitude, knowledge and practice of the motorcyclists revealed that wearing a helmet could be looking funny to some of the motorcyclists, could be disturbing, induces hotness especially in humid and tropical cities, and blocks hearing, as well. Embarrassing while wearing a helmet was mentioned by some participants. Odds ratio was calculated for both the groups independently, the odds of the criteria in safe community group vs. other group were considered. In two items namely generating hotness and hearing blockage while using the helmet, the odds ratio was significant between two groups. Data show that the odds for generating hotness in the safe community practicing cities was 7.1, and the odds for hearing blockage in safe community non-practicing cities was 0.65 after age adjustment. In this study Khorasan province with more than $65 \%$ of the motorcyclists has the highest number of motorcycle among the three provinces. Bushehr province placed at the north border of the Persian Gulf has 21\% of the motorcyclists and Fars province has the least number of motorcyclists with the proportion rate of $13 \%$. Within the each province, two groups of cities were selected. Group one, which is also considered as a case, is those cities where the safe community model is practicing for injury prevention. Except for the Bushehr and Fars province where the impact of safe community to the motorcyclists' death could not be demonstrated, the safe community of Khorasan, has a positive effect to the motor- 
cyclists' death. In Khorasan, the number of motorcycles is more in safe communities practicing cities (55.4\%) and less in non-practicing safe communities (44.6\%). But the death rate of motorcyclists are less in safe communities of Khorasan including Kashmar and Bardscan where both are internationally designated as a safe community by the WHO collaborating center for safety promotion since 2007, 2008 respectively (47\%). The study was performed in Arsanjan about the safety of motorcycle in Fars province. 1286 motorbikes participated, 7.9\% had helmet, and $92.1 \%$ did not, 35\% of them had their own helmet and $6.4 \%$ of them use it regularly.

$7.5 \%$ of them said it was heavy and bothering, and $78.4 \%$ of them were aware of benefit use of the helmet. Data showed that the lowest motorcycle accident recorded in Eghlid with 28 percent and the highest rate was recorded from the Niriza city with 42 percent. The difference was statistically significant [23] [29]-[31].

The non-practicing safe communities in the Khorasan province are Ferdos city \& Torbat-e-Hydarieh city. In these two cities death rate of motorcyclists (53\%) is high.

Although the same picture is detectable in Fars province. Arsanjan city and Eglid city are two cities that the safe community model is practicing; the Arsanjan is designated as an international safe community on 2008. Impact of the safe communities to the motorcyclists' death is positive in these two cities compare to other cities of the province, which the safe community model is not practicing. They are Kazeron city and Niriz city (44.5\% vs. 55.5\%) but in terms of the death rate, there could not be any differences between two groups of cities revealed.

The story is slightly different in Bushehr province. First of all the Bushehr port city is cited at the northern border of the Persian Gulf in the south of Iran; it is considered as the oldest port in Iran. It is also the capital city of the Busher province. Since the high number of immigration, the population age and sex composition turns over rapidly. The population density is high too. These criteria make the city unique within the province. The safe community program started very early in the city but due to many factors; the program did not run well.

The positive impact of the safe community model to the death rate of motorcyclists could not be demonstrated and in some instances, we can conclude a negative impact.

Statistically no differences were determined in Safe community practicing cities and none practicing safe community in Busher province in terms of fatality from a motorcycle accident. In Fars province, number of death from motorcycle accidents is slightly higher in non-practicing safe community than in practicing safe community. This may because of better data gathering system in the later than the former. However, statistically this finding was not significant. The situation is slightly deviated in Khorasan province. The safe community practicing cities are safer than the non-practicing safe community is for motorcyclists.

Factors related to the individual level, such as alcohol consumption, remain by far the main determinants in injury severity. Law enforcement and, above all, building the perception of alcohol as danger-catalyst rather than social-catalyst would turn into advantages, not only for these injuries.

When planning programs for motorcycle injury prevention, timing and groups more in need should be taken into account. Effective alliances are needed for multiple policies at local and national levels, including public and private partnerships, to link the fields of public health, health care, transportation, law enforcement, engineering, and education [19] [28] [30] [32]. Specifically, safety measures such as protective clothing for leg and forearm, reflectors, and structural modifications of the motorcycle like side air bags are just some of the aspects that should be considered and made available at a price affordable by all the motorcyclists, without a further increase of socio-economic differences in health outcomes.

\section{Conclusions}

Sustainability of the safe community model is an important factor to have a positive impact to the motorcyclists' death.

As the whole finding the death rate from the motorcyclists is high; young male adults of 15 - 40 are the most victims of motorcycle accidents in both the communities (comparable with the world report). Except for the Khorasan safe community, which was, started on 1997 the other safe communities had no preventing phenomenon on motorcyclists' death compared to the fellow cities of non-practicing safe community. The United Nation General Assembly has proclaimed 2011 to 2020 as the Decade of Action for Road Safety. Promoting helmet usage among motorcyclists has been recognized as one of the single most cost-effective interventions [20] [30] [33]. It will be a benefit to make the decade ahead safer for motorcyclists. 


\section{Adding to the Field}

This study reconfirms the positive impact of safe community program on motorcyclists' safety. Findings of this study are a strong motivator for those communities who are not convinced with safe community approach for safety promotion and still facing problem with motorcyclist's injury. They may reconsider safe community model for their countries.

\section{References}

[1] Ameratunga, S., Hijar, M. and Norton, R. (2006) Road Traffic Injuries: Confronting Disparities to Address a Global Health Problem. Lancet, 367, 1533-1540. http://dx.doi.org/10.1016/S0140-6736(06)68654-6

[2] Mohan, D. (2002) Road Safety in Less-Motorized Environments: Future Concerns. International Journal of Epidemiology, 31, 527-532. http://dx.doi.org/10.1093/ije/31.3.527

[3] World Health Organization (WHO) (2004) World Report on Road Traffic Injury Prevention. WHO, Geneva.

[4] Murray, C.J.L. and Lopez, A.D. (1996) The Global Burden of Disease: A Comprehensive Assessment of Mortality and Disability from Diseases, Injuries and Risk Factors in 1990 and Projected to 2020. Harvard School of Public Health, Boston.

[5] Sosin, D.M., Sacks, J.J. and Holmgreen, P. (1990) Head Injury-Associated Deaths from Motorcycle Crashes. JAMA, 264, 2395-2399. http://dx.doi.org/10.1001/jama.1990.03450180059029

[6] Valent, F., Schiava, F., Savonitto, C., Gallo, T., Brusaferro, S. and Barbone, F. (2002) Risk Factors for Fatal Road Traffic Accidents in Udine, Italy. Accident Analysis and Prevention, 34, 71-84. http://dx.doi.org/10.1016/S0001-4575(00)00104-4

[7] Nantulya, V.M. and Reich, M.R. (2002) The Neglected Epidemic: Road Traffic Injuries in Developing Countries. BMJ, 324, 1139-1141. http://dx.doi.org/10.1136/bmj.324.7346.1139

[8] Pensola, T.H. and Valkonen, T. (2000) Mortality Differences by Parental Social Class from Childhood to Adulthood. Journal of Epidemiology and Community Health, 54, 525-529. http://dx.doi.org/10.1136/jech.54.7.525

[9] Pang, T.Y., Umar, R.S. and Harwant, S. (2001) Vulnerability of the Lower Limb in Non-Fatal Motorcycle Injuries. Medical Journal of Malaysia, 56, 9-11.

[10] Haddon Jr, W. (1980) Option for the Prevention of Motor Vehicle Crash Injury. Israel Journal of Medical Sciences, 16, 45-65.

[11] American Medical Association (2005) Report 6 of the Council on Scientific Affairs (I-98). Options for Improving Motorcycle Safety. Internet Consultation.

[12] Liu, B.C., Ivers, R., Norton, R., Blows, S. and Lo, S.K. (2009) Helmets for Preventing Injury in Motorcycle Riders (Review). The Cochrane Library 2009, Issue 1.

[13] Moghisi, A.R., Afsari, M., et al. (2004) Manual for Safe Community. Ministry of Health and Medical Education, Tehran, Iran.

[14] Tavris, D.R., Kuhn, E.M. and Layde, P.M. (2001) Age and Gender Patterns in Motor Vehicle Crash Injuries: Importance of Type of Crash and Occupant Role. Accident Analysis \& Prevention, 33, 167-172. http://dx.doi.org/10.1016/S0001-4575(00)00027-0

[15] Spinks, A., Turner, C., Nixon, J. and McClure, R.J. (2009) The "WHO Safe Communities" Model for the Prevention of Injury in Whole Populations (Review). John Wiley \& Sons, Ltd., Hoboken.

[16] Naghavi, M. (2006) Mortality Pattern in 23 Provinces-2003 (in Farsi). The Iranian Ministry of Health \& Medical Education-Deputy of Health. International Road Federation (IRF). World Road Statistics. www.irfnet.org

[17] Sirathranont, J. and Kasantikul, V. (2003) Mortality and Injury from Motorcycle Collisions in Phetchaburi Province. Journal of the Medical Association of Thailand, 86, 97-102.

[18] Socialstyrelsen (National Board of Health and Welfare) (1986) KS87 Swedish Version of International Classification of Diseases. 9th Revision, Stockholm.

[19] Rutter, D.R. and Quine, L. (1996) Age and Experience in Motorcycling Safety. Accident Analysis \& Prevention, 28, 15-21. http://dx.doi.org/10.1016/0001-4575(95)00037-2

[20] UNICEF Info by Country. At a Glance: Iran (Islamic Republic of)—The Big Picture. http://www.unicef.org/infobycountry/iran.html

[21] McCaa, R. and Ruggles, S. (2002) The Census in Global Perspective and the Coming Micro Data Revolution. In: Carling, J., Ed., Nordic Demography: Trends and Differentials, Vol. 13, Scandinavian Population Studies, Unipub/Nordic Demographic Society, Oslo, 7-30. 
[22] World Health Organization (2006) Helmets: A Road Safety Manual for Decision-Makers and Practitioners. WHO, Geneva.

[23] World Health Organization (2002) GBD2002 Global Burden of Disease.

[24] World Health Organization (WHO) (2006) Country Cooperation Strategy for WHO and the Islamic Republic of Iran. World Health Organization, Regional Office for Eastern Mediterranean, Cairo, EM/ARD/012/E/R.

[25] Adekoya, N., Thurman, D.J., White, D.D. and Webb, K.W. (2002) Surveillance for Traumatic Brain Injury DeathsUnited States, 1989-1998. Morbidity and Mortality Weekly Report. Surveillance Summaries, 51, 1-14.

[26] Hasselberg, M. (2004) The Social Patterning of Road Traffic Injuries during Childhood and Youth. National Longitudinal Register-Based Studies. Karolinska Institutet, Department of Public Health Sciences, Division of Social Medicine, Stockholm.

[27] Lindqvist, K., Timpka, T. and Schelp, L. (2001) Evaluation of Inter-Organizational Traffic Injury Prevention in a WHO Safe Community. Accident Analysis \& Prevention, 33, 599-607. http://dx.doi.org/10.1016/S0001-4575(00)00071-3

[28] International Road Traffic and Accident Database. http://cemt.org/IRTAD/IRTADPublic/index.htm

[29] Frahmand, M. and Sayadi, M. (2011) The Evaluation of Motorbikes Security in Arsanjan, Eqlid, Kazeron and Neiriz. Scientific Information Database (SID). http://www.sid.ir/

[30] Rahkonen, O., Arber, S. and Lahelma, E. (1995) Health Inequalities in Early Adulthood: A Comparison of Young Men and Women in Britain and Finland. Social Science \& Medicine, 41, 163-171. http://dx.doi.org/10.1016/0277-9536(94)00320-S

[31] Department for Transport (1998) Transport Statistics: Motorcycle Road Accidents: Great Britain 1998. Department for Transport, London.

[32] Statistical Center of Iran. http://eamar.sci.org.ir/

[33] Collins, M., Lovell, M.R., Iverson, G.L., Ide, T. and Maroon, J. (2006) Examining Concussion Rates and Return to Play in High School Football Players Wearing Newer Helmet Technology: A Three-Year Prospective Cohort Study. Neurosurgery, 58, 275-286. http://dx.doi.org/10.1227/01.NEU.0000200441.92742.46 
Scientific Research Publishing (SCIRP) is one of the largest Open Access journal publishers. It is currently publishing more than 200 open access, online, peer-reviewed journals covering a wide range of academic disciplines. SCIRP serves the worldwide academic communities and contributes to the progress and application of science with its publication.

Other selected journals from SCIRP are listed as below. Submit your manuscript to us via either submit@scirp.org or Online Submission Portal.
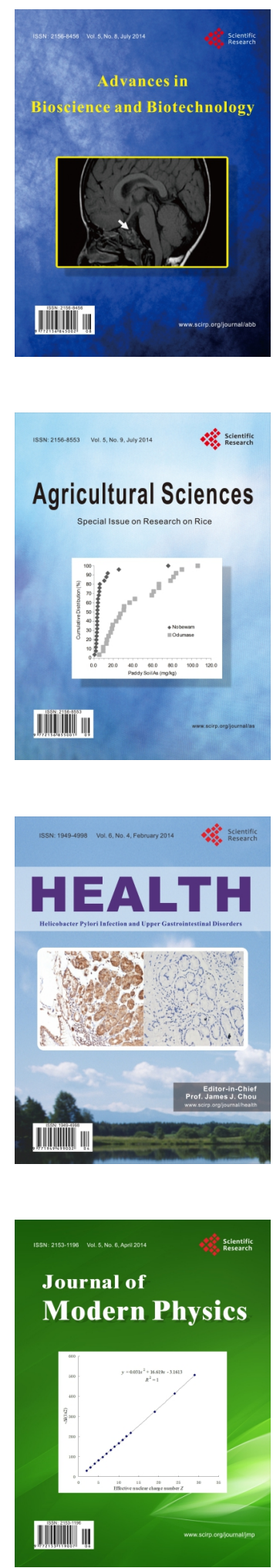
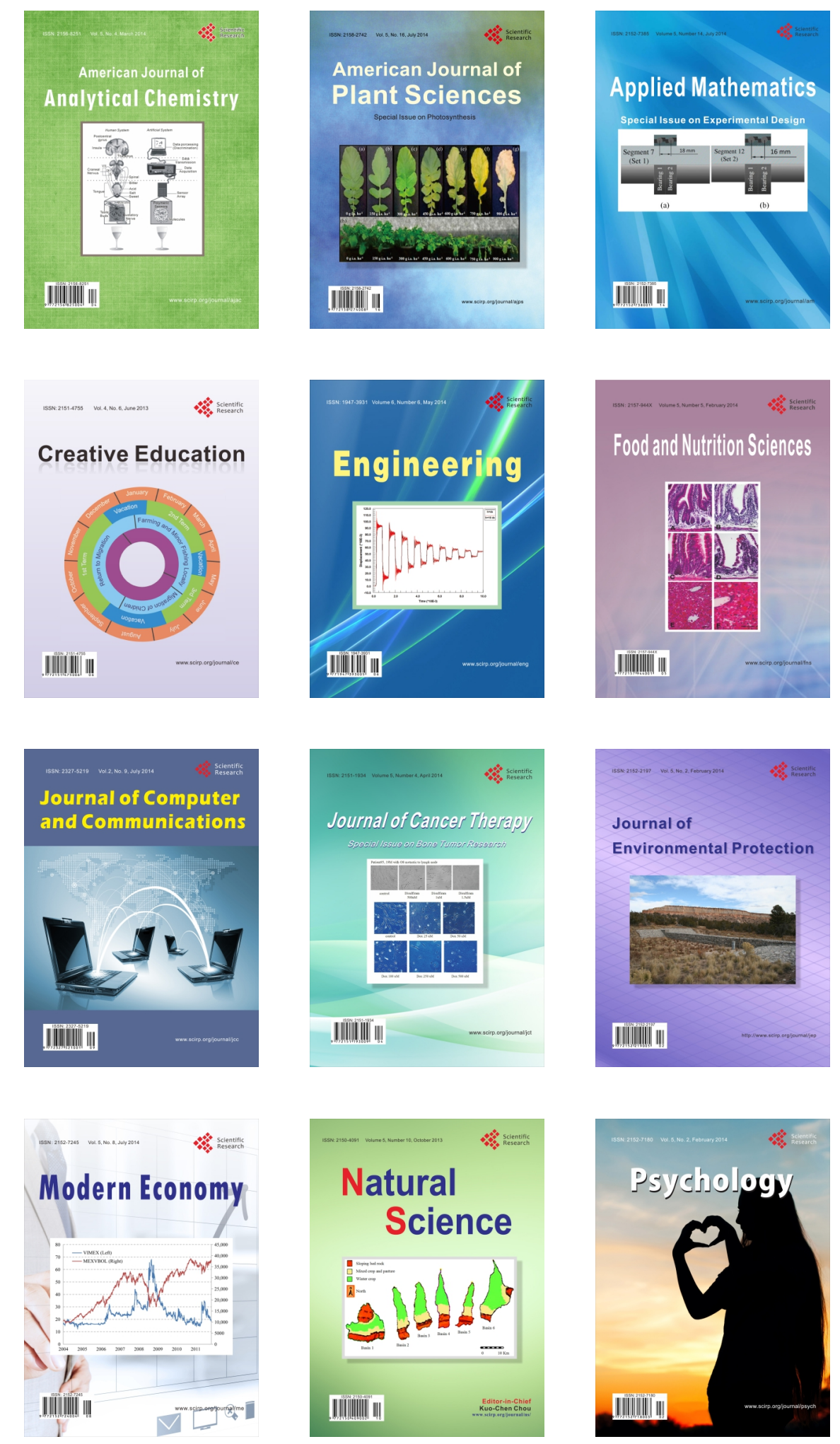